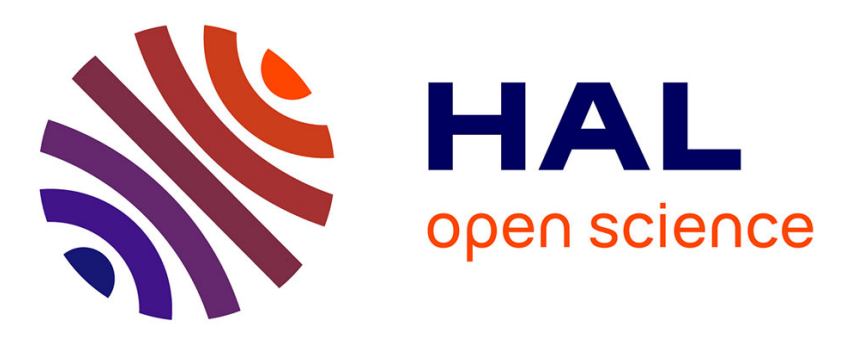

\title{
Inversion-based control of electromechanical systems using causal graphical descriptions
}

Pierre-Jean Barre, Alain Bouscayrol, Philippe Delarue, Eric Dumetz, Frederic

Giraud, Jean-Paul Hautier, Xavier Kestelyn, Betty Lemaire-Semail, Eric

Semail

\section{To cite this version:}

Pierre-Jean Barre, Alain Bouscayrol, Philippe Delarue, Eric Dumetz, Frederic Giraud, et al.. Inversion-based control of electromechanical systems using causal graphical descriptions. IEEE International Conference On Industrial Applications of Electronics, Nov 2006, PARIS, France. pp.52765281, 10.1109/IECON.2006.347781 . hal-01109564

\section{HAL Id: hal-01109564 \\ https://hal.science/hal-01109564}

Submitted on 2 Feb 2015

HAL is a multi-disciplinary open access archive for the deposit and dissemination of scientific research documents, whether they are published or not. The documents may come from teaching and research institutions in France or abroad, or from public or private research centers.
L'archive ouverte pluridisciplinaire HAL, est destinée au dépôt et à la diffusion de documents scientifiques de niveau recherche, publiés ou non, émanant des établissements d'enseignement et de recherche français ou étrangers, des laboratoires publics ou privés. 


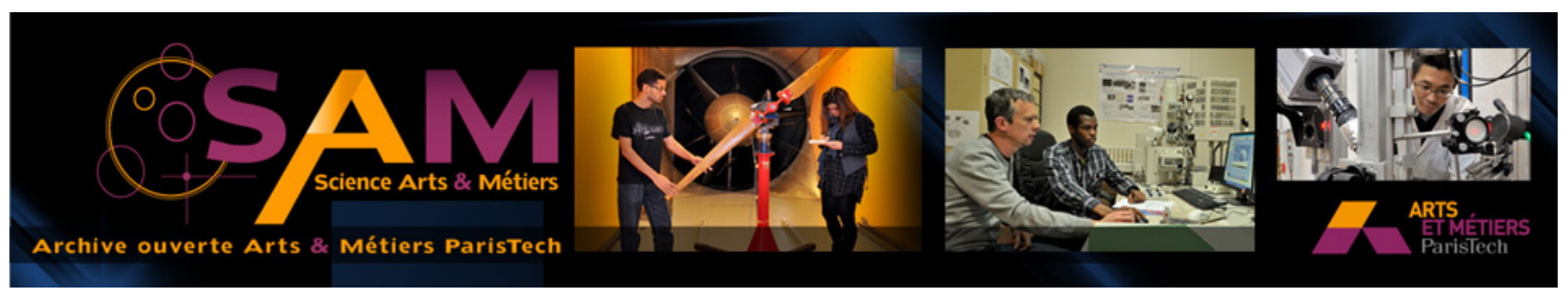

\section{Science Arts \& Métiers (SAM)}

is an open access repository that collects the work of Arts et Métiers ParisTech researchers and makes it freely available over the web where possible.

This is an author-deposited version published in: http://sam.ensam.eu

Handle ID: .http://hdl.handle.net/10985/9276

\section{To cite this version :}

Pierre-Jean BARRE, Alain BOUSCAYROL, Philippe DELARUE, Eric DUMETZ, Frederic GIRAUD, Jean-Paul HAUTIER, Xavier KESTELYN, Betty SEMAIL, Eric SEMAIL - Inversionbased control of electromechanical systems using causal graphical descriptions - In: IEEE International Conference On Industrial Applications of Electronics, France, 2006-11 - IEEE International Conference On Industrial Applications of Electronics - 2006 


\title{
Inversion-based control of electromechanical systems using causal graphical descriptions
}

\author{
P. J. Barre, A. Bouscayrol, Member, IEeE, P. Delarue, E. Dumetz, F. Giraud, J. P. Hautier, X. Kestelyn, \\ B. Lemaire-Semail, Member, IEEE, E. Semail, Member, IEEE \\ University of Lille, L2EP, USTL, 59655 Villeneuve d'Ascq, France, Betty.Semail@polytech-lille.fr
}

\begin{abstract}
Causal Ordering Graph and Energetic Macroscopic Representation are graphical descriptions to model electromechanical systems using integral causality. Inversion rules have been defined in order to deduce control structure step-bystep from these graphical descriptions. These two modeling tools can be used together to develop a two-layer control of system with complex parts. A double-drive paper system is taken as an example. The deduced control yields good performances of tension regulation and velocity tracking.
\end{abstract}

\section{INTRODUCTION}

Causal Ordering Graph (COG) has been introduced ten years ago [1][2] to describe power electronics and electrical machines for developing their control. This graphical description uses integral causality to organize a causal graph of variables. The inversion of this graph yields the control structure of the system with measurements and controllers.

Energetic Macroscopic Representation (EMR) has been introduced in 2000 to describe complex electromechanical drives, especially multi-drives systems [3]. EMR is based on action reaction principle, which organizes the system as interconnected sub-systems according to the integral causality. An inversion of this description leads to macro-control blocs.

In this paper, Causal Ordering Graph and Energetic Macroscopic Representation are coupled for a double-layer control of complex electromechanical drives. A double-drive paper system is chosen as an example. The global control of the system is deduced from EMR and the local velocity control of the band tension is deduced from the COG according to Hook's law. Simulation results highlight the interest of this double-layer control for increasing dynamics of actual systems without complex and advanced control methods.

\section{Causality ANd Graphical Description}

\section{A. Causal modeling}

A System is composed of inputs and outputs. Its modeling consists in expressing outputs from inputs.

Electromechanical systems can be decomposed into elementary interconnected elements, which manage energy: dissipation, storage and transformation. All sub-systems can be modeled using differential equations with state variables. These variables are associated with energy and are dependent on inputs and time according to integral causality [1][4][5]. When inputs change, the state variables reach other steady states after transient states: outputs are always consequence of inputs.

The natural causality is the integral causality because it respects the energy flowing considering the state variables as delayed from their inputs. Integral causal modeling leads then to a more physical description. Derivative causality is sometimes used in simulation because it avoids expressing all elements according to the integral causality. Some association problems in complex systems are thus solved [6]. But derivative causality yields a longer computation time.

\section{B. Causal Ordering Graph (COG)}

The causal ordering graph is a graphical description based on the integral causality [1][2]. On the contrary of BondGraph [6], COG doesn't authorize the derivative causality.

Two kinds of relationships are considered: rigid relationships without any time dependence between output and input. That means that an input change instantaneously leads to an output change. There is no delay. A rigid relationship is depicted by an orange balloon involving a double arrow inside: as there is no time dependence, input and output can be easily permutated. For example, the Ohm's law connects a current $i_{R}$ and a voltage $u_{R}$ through a rigid relationship using the resistance $R$ (Fig. 1a):

$u_{R}=R i_{R} \quad$ or $\quad i_{R}=\frac{1}{R} u_{R}$

Causal relationships are associated with time-dependence equations. According to the integral causality, the output is mandatory an integration of the input. This kind of relationship is depicted by orange balloons with a single arrow inside: output and input cannot be permutated and there is a delay between them. For example, the inductor relationship links the voltage $u_{L}$ and the current $i_{L}$ through a causal relationship using the inductance $L$ (Fig. 1b).

$\frac{d}{d t} i_{L}=\frac{1}{L} u_{L} \quad$ or $\quad i_{L}=\frac{1}{L} \int u_{L} d t+i_{L}(0)$

All linear elements can be depicted using these two kinds of relationships connected by their inputs and outputs.

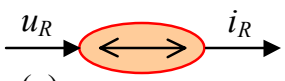

(a)

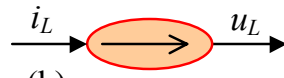

(b)
Fig. 1: COG with rigid (a) and causal (b) relationships 


\section{Energetic Macroscopic Representation (EMR)}

EMR is a more macroscopic description, based on the action and reaction principle. All subsystems are connected by action and reaction variables, whose product yields the exchanged power. As for COG, internal descriptions of elements are defined according to the integral causality.

Three kinds of elements are defined. Sources (green oval pictograms) are terminal elements, which deliver and/ or receive energy. Accumulation elements (orange rectangular pictograms) store energy, which leads to state variables. For example a capacitor stores potential energy, which is proportional to the square of its voltage $u_{C}$; this voltage is a state variable controlled by the upstream and downstream currents $i_{u p}$ and $i_{\text {down }}$ (Fig. 2a):

$\frac{d}{d t} u_{C}=\frac{1}{C}\left(i_{u p}-i_{\text {down }}\right)$

Conversion elements convert energy without energy accumulation. They are described by squares (electrical conversion), circles (electromechanical conversion) or triangles (mechanical conversion). For example a four-quadrant chopper is a conversion element, which modulates output voltage $u_{\text {chop }}$ from DC supply voltage $V_{D C}$ using the modulation ratio $m_{\text {chop }}$, and reaction current $i_{\text {chop }}$ from the load current $i_{\text {load }}$ (Fig. 2b):

$$
\left\{\begin{array}{l}
u_{\text {chop }}=m_{\text {chop }} V_{D C} \\
i_{\text {chop }}=m_{\text {chop load }}
\end{array}\right.
$$

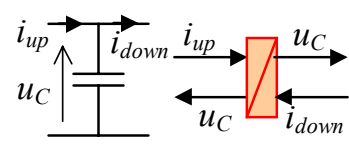

(a)

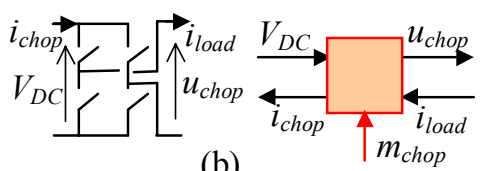

(b)
Fig. 2: Accumulation (a) and conversion (b) elements of EMR

Moreover coupling devices are introduced to distribute energy [3]. They are depicted by interleaved pictograms.

\section{InVERSION-BASED CONTROL METHODOLOGY}

\section{A. Inversion Principle}

The modeling of the system leads to express the output $y(t)$ as a function of the input $u(t)$ using integral causality.

The control structure has to define the adapted input to act on the system in order to produce the expected output (Fig. $3)$. In fact, the control has to express the tuning input $u_{\text {tun }}(t)$ as a function of the output set point $y_{\text {ref }}(t)$. Thus the control has to invert the power function of the system.

For defining the control structure, we have to find the algorithm to use and the measurement to do on the system.

This inversion principle is applied to each sub-systems defined by COG or EMR. There are 3 basic inversion rules.

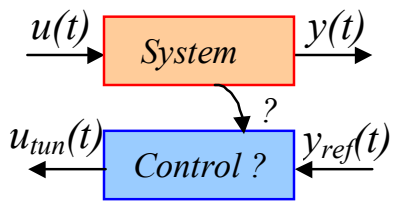

Fig. 3: Inversion principle

Single-input rigid relationships - In this case a direct inversion can be used if the relationship is well defined. For example (Fig. 4.a):

$$
y(t)=k u(t) \rightarrow u_{t u n}(t)=\frac{1}{k} y_{r e f}(t)
$$

This inversion requires neither measurement nor controller.

Multiple-inputs rigid relationships - If we choose to act on one input to impose the output, the other inputs become disturbances. They have to be measured or estimated to define the tuning input $u_{\text {tun }}(t)$ from the output set point $y_{\text {ref }}(t)$. For example (Fig. 4.b):

$y(t)=u_{1}(t)+u_{2}(t) \rightarrow u_{\text {ltun }}(t)=y_{\text {ref }}(t)-u_{2 \text { mes }}(t)$

If no controller is required, disturbance input must be measured or estimated.

Single-input causal relationships - The direct inversion of such a relationship leads to a derivation, which has a nonphysical causality. In order to solve this problem, an indirect inversion is made using a controller. In this case, the output has to be measured. For example, using a simple P controller with gain $K_{p}$ (Fig. 4c)

$$
\begin{aligned}
y(t)=\int u(t) d t+y(0) & \rightarrow \\
u_{\text {tun }}(t) & =K_{p}\left[y_{\text {ref }}(t)-y_{\text {mes }}(t)\right]
\end{aligned}
$$

. In this third case, a controller and the measurement of the output are required.

Others relationships - For non-linear, or not welldefined rigid relationships, a direct inversion is not always possible. Controllers can be used too. Most of other relationship can be decomposed into the 3 basic relationships. Their control is thus a combination of the 3 basic control laws.

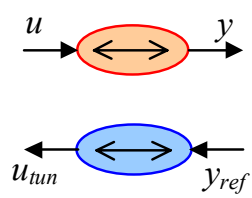

(a)

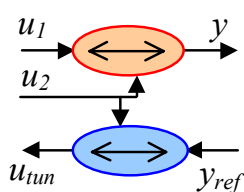

(b)

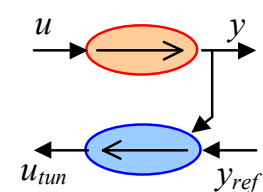

(c)
Fig. 4: Basic inversions depicted by $C O G$

Application to COG - In the COG description, the control sub-systems are depicted by blue oval pictograms. Direct inversion contains a double arrow inside and controller con- 
tains a single arrow.

Application to EMR - All control subsystems are depicted by blue parallelograms because they only handle information. Controllers contain an oblique bar inside.

\section{B. Maximum control structure}

This control structure is obtained by a step by step inversion of the system decomposed into elementary sub-systems. Such a control is obtain by the following stages:

1. Decomposition of the system into elementary sub-systems.

2. Determination of the tuning chain: from the tuning input to the global output to be controlled.

3. Inversion step by step of the tuning chain using the previous inversion rules.

All variables are first considered as measurable. At this stage the control structure requires a maximum of controllers and sensors. For this reason, it is called maximum control structure. This control scheme is composed of cascaded loops, which enable limitation of internal variables.

This control can be obtained using COG or EMR. Generally, EMR is well adapted for complex systems. COG can be used to invert a sensitive part of EMR (see section IV).

It may be noted that other inversion rules are required for coupling devices, as distribution and weighting criteria [7].

\section{Practical control structure}

The maximum control structure is not always adapted for a real time implementation. More practical control structures can be deduced using the following stages:

1. Simplifications of the control (merging of control blocs, avoiding explicit rejection of disturbance...).

2. Estimation of non-measured variables.

Finally, the controller can be tuned and the real time implementation can be done.

\section{Application to a Double-drive Paper System}

\section{A. Double-drive system for paper processing}

The system is composed of an unwinding roll and winding roll (Fig. 5). A paper band is processed between both rolls.

Each roll is moved by an induction machine, which is supplied by a voltage-source inverter (VSI). Both power converters are supplied by a diode rectifier from the grid, but this common supplied is not considered in this paper. We assume that VSI are supplied by independent DC voltages.

There are two objectives for such a double-drive system. First, the tension of the band has to be regulated to a constant value for the quality of the paper processing. Secondly, the velocity of the winding roll has to be well managed for the quality of the final paper roll [9].

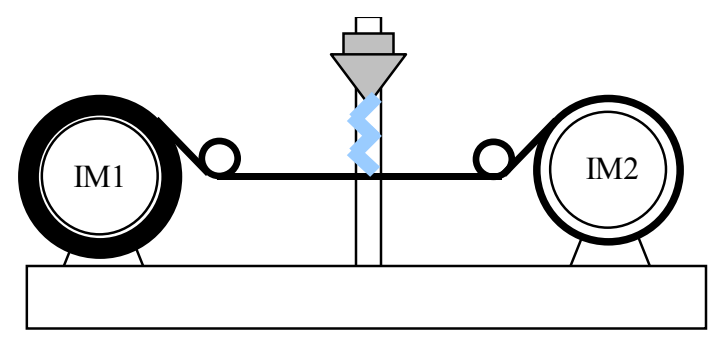

Fig. 5: Paper processing system

\section{B. Graphical modeling of the double drive system}

As a lot of drive applications have been already studied using COG and EMR, only the mechanical part is detailed. Global EMR is depicted in Fig. 6.

Electrical source - The equivalent dc voltage is assumed to be the electrical source (green oval pictogram), which provides the voltage $V_{D C}$ to the system.

Induction machines and inverters - Their EMR can be summarized in three blocks. The first one is an electrical converter (square) associated with the voltage source inverter. The second one (rectangle) represents the equivalent stator windings in this frame. The last block deals with electromechanical conversion (circle), which yields the torque $T_{i m}$. Relationships of each element and details of EMR can be found in [8]. It is just another way to describe the machine in the $(d, q)$ frame from the same classical relationships.

Globally, the induction machine is connected to the inverter by the supplied voltage $\underline{u}_{v s i}$ and reacts by the currents $\underline{i}_{i m}$. The machine leads to impose the torque $T_{i m}$ on the mechanical part, which reacts by the rotation speed $\Omega_{\text {shaft }}$.

Shafts and rolls - A machine shaft is an energy accumulation element, which yields the rotation speed $\Omega_{\text {shaft }}$ from the machine torque and the roll torque $T_{\text {roll: }}$

$J \frac{d}{d t} \Omega_{\text {shaft }}=T_{\text {im }}-T_{\text {roll }}-f \Omega_{\text {shaft }}$

where $J$ and $f$ are the moment of inertia and the friction coefficient of the shaft, including the rotor and the driven roll, assuming rigid coupling.

The rolls ensure the conversion from a rotational motion to a linear motion. They are mechanical converters (triangular pictograms), which yield the roll velocity $v_{\text {roll }}$ and torque from the shaft speed and the band tension $T_{\text {band }}$ :

$\left\{\begin{array}{l}v_{\text {roll }}=R_{\text {roll }} \Omega_{\text {shaft }} \\ T_{\text {roll }}=R_{\text {roll }} T_{\text {band }}\end{array}\right.$

where $R_{\text {roll }}$ is the radius of the roll.

Paper bands - The band of paper has to be taken into account. It is modeled from simplified Hook's law [9]: 


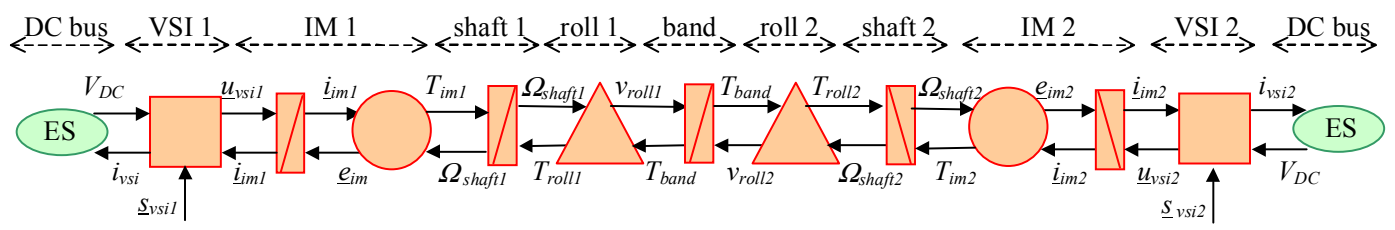

Fig. 6: EMR of the double drive system

$$
\begin{aligned}
L \frac{d}{d t} T_{\text {band }} \approx E S & \left(v_{\text {roll } 2}-v_{\text {roll } 1}\right) \\
& -T_{\text {band }}\left(2 v_{\text {roll } 1}-v_{\text {roll } 2}\right)
\end{aligned}
$$

with $L$ the band length, $S$ the band section and $E$ the Young modulus of the paper. A paper band connects two drives with a non-linear elastic phenomenon. This leads to problems, which have to be solved by complex algorithms.

A COG is used to organize this complex relationship for control purpose. Intermediary variables are defined:

$$
\begin{aligned}
& u=\left(E S+2 T_{\text {band }}\right) v_{\text {roll } 1} \\
& w=\left(E S+T_{\text {band }}\right) v_{\text {roll } 2} \\
& y=u-w \\
& L \frac{d}{d t} T_{\text {band }}=y
\end{aligned}
$$

This new description leads to three rigid and one causal relationships COG (Fig. 7). These simple equations can now easily be inverted (see section V).

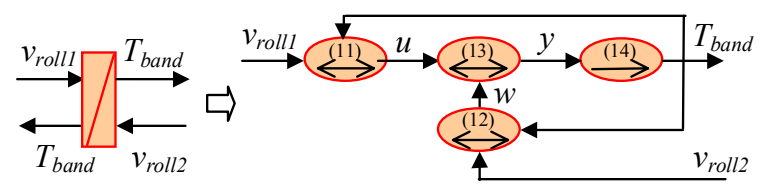

Fig. 7: COG and EMR of the paper band

\section{Inversion-based control of the double-drive system}

We assume constant radius of rolls, constant inertia of shafts and constant elasticity. More advanced controls are used to take their variations into account [10] [11] [12], one of them is obtained by an extension of the EMR [13].

The Maximum Control Structure (MCS) of the doubledrive system is deduced from the EMR. Two tuning chains are defined. The first one leads to control the band tension $T_{\text {band }}$ from the switching orders of inverter VSI $1 \underline{S}_{v s i}$. The second tuning chain lead to control the velocity $v_{\text {roll }}$ from the switching orders of inverter VSI $2 \underline{s}_{v s i}$.

The MCS is obtained by an inversion step-by-step of the both tuning chains (Fig. 10). The first part is associated with the tension control using a tension controller, a speed controller, the machine and inverter controls. The second part leads to the roll velocity control with a speed controller, the machine and inverter controls.

Inversions of VSI and induction machines - Inverters are inverted using a classical Pulse Width Modulation. Induction machines are inverted using a classical Field Oriented Control. More details are reported in [8].
Inversions of shafts - As a shaft is an accumulation element with integral relationships (8), a controller is required. Inversion of (8) yields the reference torque $T_{\text {im_ref }}$ using an explicit compensation of roll torque $T_{\text {roll }}$ :

$$
T_{\text {im_ref }}=C\left[\Omega_{\text {shaft_ref }}-\Omega_{\text {shaft_mes }}\right]+T_{\text {roll_mes }}
$$

Where $C\left[X_{\text {ref }}-X_{\text {mes }}\right]$ is a controller, which could be PI, IP, PID or other type. A classical decomposition can be made using COG (Fig. 8). Most of accumulation elements are inverted by this way [8].

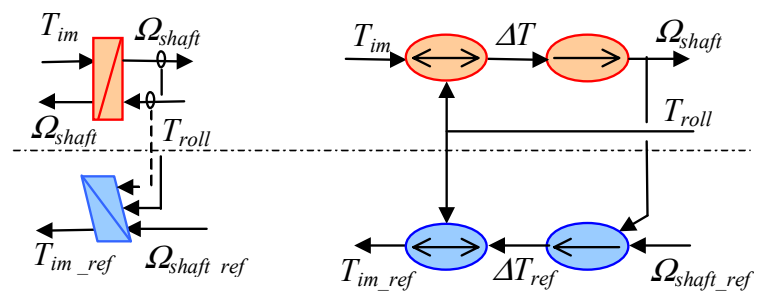

Fig. 8: EMR and COG of the speed control

Inversions of rolls - A direct inversion of relationship (9) leads to the reference of rotation speed $\Omega_{\text {shaft }}$ ref from the reference of the roll velocity $v_{\text {roll_ref }}$ :

$\Omega_{\text {shaft_ref }}=\frac{1}{R_{\text {roll }}} v_{\text {roll_ref }}$

A decomposition can be made using COG (Fig. 9). Most of conversion elements are inverted by this way [8].

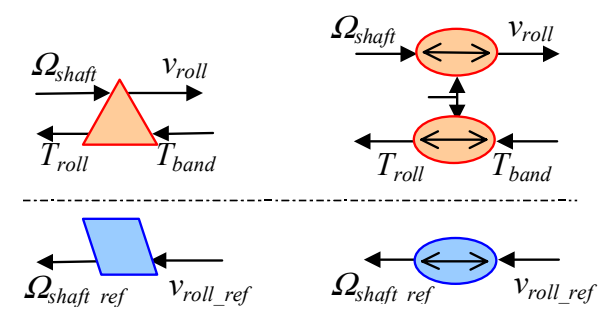

Fig. 9: EMR and COG of the roll inversion

Inversions of paper band - The inversion of the paper band is more complex. The COG organizes the inversion of each decomposed relationship from (11) to (14) to obtain:

$$
\begin{aligned}
& v_{\text {roll1_ref }}=\frac{u_{\text {ref }}}{\left(E S+2 T_{\text {band_mes }}\right)} \\
& w_{\text {est }}=\left(E S+T_{\text {band_mes }}\right) v_{\text {roll2_mes }}
\end{aligned}
$$




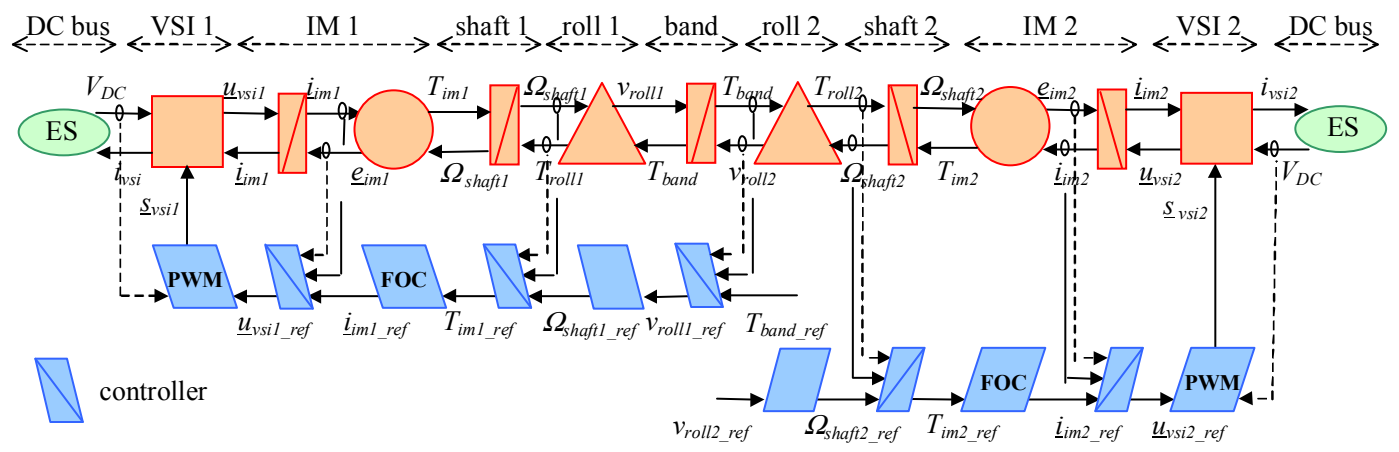

Fig. 10: Maximum control structure of the double drive system

$u_{r e f}=y_{\text {ref }}+w_{\text {est }}$

$y_{\text {ref }}=C\left[T_{\text {band_ref }}-T_{\text {band_mes }}\right]$

In this case, the COG leads to one controller to define $y_{\text {ref }}$, a compensation of $w_{\text {est }}$ and a compensation of $T_{\text {band }}$. The influence of compensations is discussed in section D.

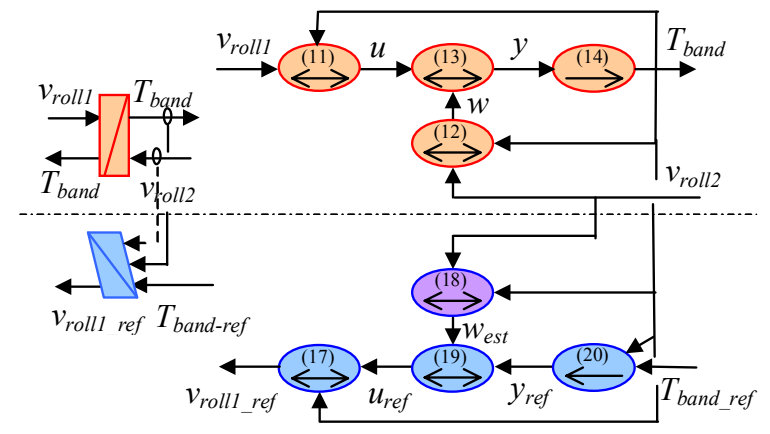

Fig. 11: EMR and COG of the band control

\section{Control performances of the double drive system}

EMR and inversion-based control can be directly transposed to Matlab-Simulink ${ }^{\mathrm{TM}}$ (Fig. 12). All controllers are PI controllers tuned with a pole placement. At first, the tension band is set at a constant value (Fig. 13). Then the velocity has a trapezoidal trajectory (Fig. 14) to start progressively. Using all compensations for the band control there are only few disturbances during velocity transient.

If the compensation of $w_{e s t}$ is avoided there is an important error for the band tension during velocity transient (Fig. 15). If this compensation is not made, a more complex controller is required [12]. However the compensation of $w_{\text {est }}$ uses the measurement of the roll velocity $v_{\text {roll } 2}$. But as in the actual process there is a great variation of the roll radius, this measurement is often required for the control of the velocity. In this case, the compensation of $w_{\text {est }}$ requires no supplementary sensor.

If the compensation of $T$ is avoided (simplification of (17) in Fig. 11), there is no change in the band tension (Fig. 16). A simplification of the control can thus be made without breaking paper during transients.

\section{Conclusion}

The inversion-based control is deduced from integral causal modeling of the systems. Graphical descriptions as COG and EMR have been developed to systematically build controls using the inversion methodology. COG is devoted to detailed description of complex elements. EMR is associated to macroscopic modeling of an overall system. Both graphical descriptions can then be used to develop a two-layer control structure of an electromechanical system having sensitive elements. Such a two-layer control is applied to a double-drive paper process. EMR is used to organize the global control and COG is focused on the paper band controller. The inversion-based control deduced from these two graphical tools yields good performances of the tension regulation and the roll velocity tracking.

Inversion-based control have been successfully used in different applications for experimental results: piezoactuators [14], tool machine, hybrid vehicle [15], polyphase machines [16], automatic subway[17], wind energy conversion systems [8]. In this application, the proposed approach yields an accurate control structure, taking into account the real physical behavior of the system and avoiding damage on the power components

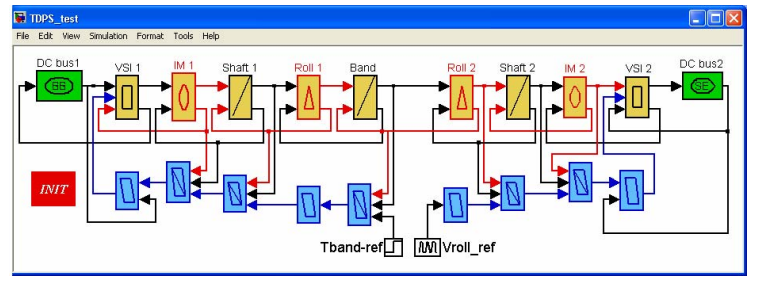

Fig. 12: Matlab-Simulink ${ }^{T M}$ model of the paper system

\section{ACKNOWLEDGMenT}

This paper has been written by permanent staff of the L2EP control team, managed by Prof. Hautier, then by Prof. Lemaire-Semail. The authors thank all Ph.D. students, who have ensured the development of the methodology on various applications. The authors thank ENI Tunis and Université de Québec à Trois Rivieres for their collaborations on textile and paper band control. 


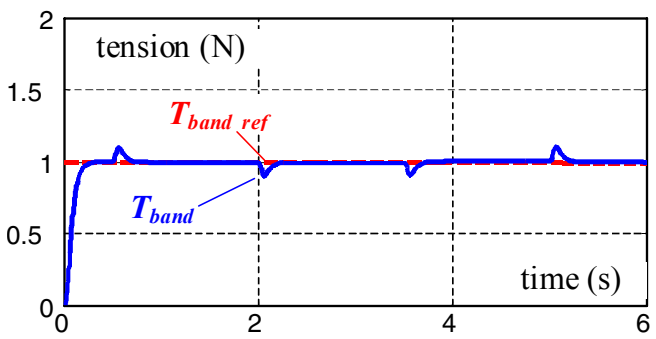

Fig. 13: Band tension with all compensations

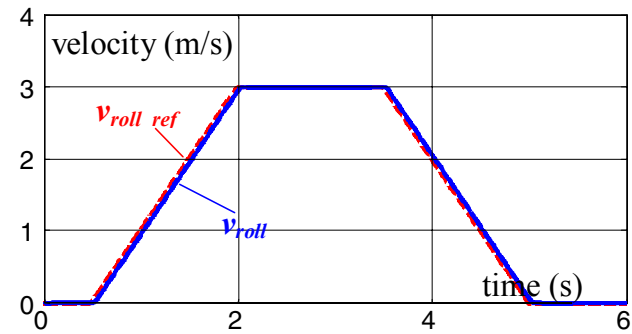

Fig. 14: Roll velocity

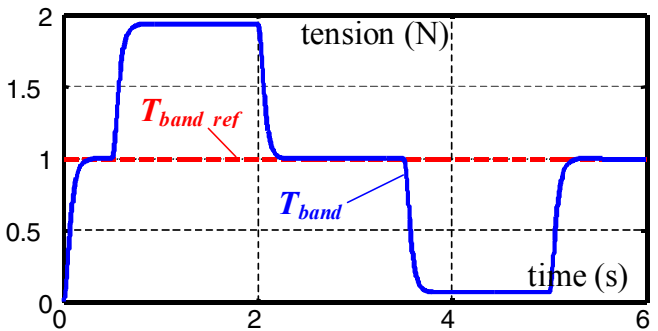

Fig. 15: Band tension without compensation of $w_{\text {est }}$

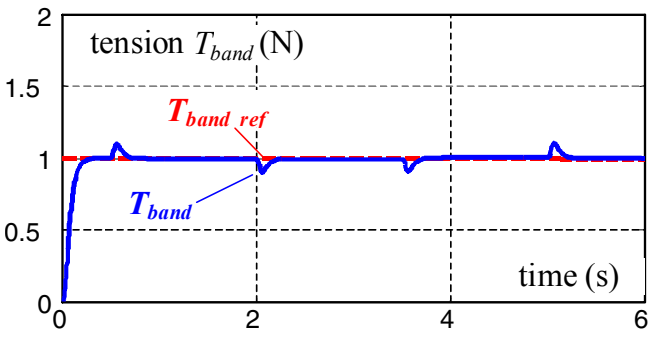

Fig. 16: Band tension without compensation of $T$

\section{REFERENCES}

[1] J. P. Hautier, J. Faucher, "Le graphe informationnel causal", Bulletin de l'Union des Physiciens, (text in French), vol. 90, juin 1996, pp. $167-189$

[2] J. P. Hautier, P. J. Barre, "The causal ordering graph - A tool for modelling and control law synthesis", Studies in Informatics and Control Journal, vol. 13, no. 4, December 2004, pp. 265-283.

[3] A. Bouscayrol, B. Davat, B. de Fornel, B. François, J. P. Hautier, F. Meibody-Tabar, M. Pietrzak-David, "Multimachine Multiconverter System: application for electromechanical drives", European Physics Journal - Applied Physics, vol. 10, no. 2, May 2000, pp. 131-147;

[4] I. Iwasaki, H. A. Simon, "Causality and model abstraction", Artificial Intelligence, Elsevier, vol. 67, 1994, pp. 143-194.

[5] Z. Rubin, S. Munns, J. Moskowa, "The development of vehicular powertrain system modeling methodologies: philosophy and implementation", System Automotive Engineering, paper 971089, 1997.

[6] H. Paynter, Analysis and design of engineering systems, MIT Press, 1961.

[7] A. Bouscayrol, B. Davat, B. de Fornel, B. François, J. P. Hautier, F. Meibody-Tabar, E. Monmasson, M. Pietrzak-David, H. Razik, E. Semail, M. F. Benkhoris, "Control Structures for Multi-machine Multi-converter Systems with upstream coupling", Mathematics and Computers in Simulation, vol. 63, no3-5, November 2003, pp. 261270.

[8] A. Bouscayrol, X. Guillaud, P. Delarue, "Hardware-in-the-loop simulation of a wind energy conversion system using Energetic Macroscopic Representation", IECON'05, Raleigh, November 2005.

[9] H. Koç, D. Knittel, M. de Mathelin, G. Abba, "Modelling and robust control of winding systems for elastic webs", IEEE Transactions on Control Systems Technology, vol.10, no. 2, March 2002, pp. 197208.

[10] S. Song, S. Sul, "A new tension controller for continuous strip processing line", IEEE Trans; on Industry Applications, Vol. 36, no. 2, March/April 2000, pp. 633-639.

[11] M.D. Baumgart, L.Y. Pao, "Robust Lyapunov-based feedback control of non-linear web-winding systems," IEEE-CDC'03, vol. 6, December 2003, pp. 6398-6405.

[12] D. Knittel, A. Arbogast, M. Vedrines, P. Pagilla, "Decentralized robust control strategies with model based feedforward for elastic web winding systems", IEEE-ACC'06, June 2006, pp.1968 - 1975.

[13] Y. Djani, P. Sicard, A. Bouscayrol, "Extension of Energetic Macroscopic Representation to time-varying systems, applications to winder tension control", IEEE-ISIE'06, Montreal, July 2006.

[14] F. Giraud, B. Lemaire-Semail, J. Aragones, J. Robineau, J. T. Audren, "Precise position control of a travelling wave ultrasonic motor", IEEE-IAS'05, Hong Kong, October 2005, vol. 3 pp. 1548-1554.

[15] W. Lhomme, P. Delarue, P. Barrade, A. Bouscayrol, "Design and control of a supercapacitors storage system for traction applications", IEEE-IAS'05, Hong-Kong, October 2005, vol. 3, pp. 2013-2020.

[16] X. Kestelyn, E. Semail, JP Hautier, "multi-phase system supplied by SVM VSI: a new fast algorithm to compute duty cycles", EPE Journal, Vol. 14, no 3, August 2004.

[17] J. N. Verhille, A. Bouscayrol, P. J. Barre, J. C. Mercieca, J. P. Hautier, E. Semail, "Torque tracking strategy for anti-slip control in railway traction systems with common supplies", IEEE-IAS'04, proceeding vol. 4. Seattle (USA), October 2004, pp. 2738-2745

\section{APPENDIX: SYNOPTIC OF COG AND EMR}

\begin{tabular}{|c|c|c|c|c|c|}
\hline$\stackrel{u}{\longleftrightarrow} \stackrel{y}{\longrightarrow}$ & $\begin{array}{l}\text { Relationship } \\
\text { without time } \\
\text { dependence }\end{array}$ & $\rightarrow$ & Source of energy & 11 & $\begin{array}{l}\text { Element with } \\
\text { energy accumulation }\end{array}$ \\
\hline 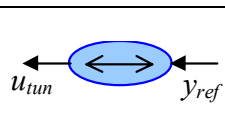 & $\begin{array}{l}\text { Direct } \\
\text { inversion }\end{array}$ & $\longrightarrow$ & $\begin{array}{l}\text { Electrical converter } \\
\text { (without energy } \\
\text { accumulation) }\end{array}$ & & \\
\hline$\stackrel{u}{\rightarrow}$ & $\begin{array}{l}\text { Relationship with } \\
\text { an integral } \\
\text { causality }\end{array}$ & & $\begin{array}{l}\text { Mechanical } \\
\text { converter (without } \\
\text { energy accumulation) }\end{array}$ & & $\begin{array}{l}\text { Control block } \\
\text { without } \\
\text { controller } \\
\end{array}$ \\
\hline$\stackrel{y_{\text {mes }}}{\longleftarrow}$ & $\begin{array}{l}\text { Indirect } \\
\text { inversion } \\
\text { using controller }\end{array}$ & 7 & $\begin{array}{l}\text { Electromechanical } \\
\text { converter (without en- } \\
\text { ergy accumulation }\end{array}$ & & $\begin{array}{l}\text { Control block } \\
\text { with } \\
\text { controller }\end{array}$ \\
\hline
\end{tabular}

